\title{
Pelvic recurrence of stage la well-differentiated endometrial carcinoma after 13 years: A case report
}

\author{
Annie Kim ${ }^{1}$, Long Nguyen ${ }^{1,2}$, Tamara Kalir ${ }^{1,2,3}$, Linus Chuang ${ }^{1,2}$ \\ ${ }^{1}$ Icahn School of Medicine at Mount Sinai, New York, USA \\ ${ }^{2}$ Department of Obstetrics, Gynecology, and Reproductive Science, Icahn School of Medicine at Mount Sinai, New York, USA \\ ${ }^{3}$ Department of Pathology, Icahn School of Medicine at Mount Sinai, New York, USA
}

\section{Abstract}

A great majority of endometrial carcinoma recurrences are observed in high-risk patients and within the first 3 years of treatment. The relapse of endometrial carcinoma occurring more than 10 years after initial treatment has rarely been described. Initially diagnosed and treated for International Federation of Gynecology and Obstetrics (FIGO) stage 1a, grade 1 adenocarcinoma, our patient presented 13 years later with an isolated pelvic recurrence, demonstrating, to our knowledge, the longest disease-free interval with recurrence in the pelvis reported in literature. After surgical resection, the patient is being considered for enrollment in a clinical trial.

Despite favorable prognostic features, it is possible to observe the recurrence of endometrial carcinoma even 5 years after surveillance and remission. Successful salvage therapies are available but may depend upon early diagnosis. (J Turk Ger Gynecol Assoc 2016; 17: 51-4)

Keywords: Endometrial carcinoma, recurrence, disease-free interval

Received: 30 August, 2015

Accepted: 01 November, 2015

Available Online Date: 12 January, 2016

\section{Introduction}

Endometrial carcinoma is the sixth most common cancer in women, with 320,000 new cases diagnosed worldwide in 2012 (1). In the United States and many developed countries, endometrial carcinoma is the most common cancer of female reproductive organs. The American Cancer Society estimated 52,630 newly diagnosed cases and 8,590 deaths due to uterine cancer in the United States in 2014 (2). Most women are diagnosed at stage 1 disease when surgery is curative and post-staging surveillance is appropriate. Patients undergoing surgical staging with or without adjuvant radiation therapy have reported recurrence rates between $3 \%$ and $15 \%$ for early-stage disease (International Federation of Gynecology and Obstetrics, FIGO, stages 1-2). Of the cases that recur, $76-87 \%$ is evident within the first 3 years of treatment initiation (3). This report describes the case of a patient who had a primary recurrence of endometrioid endometrial adenocarcinoma 13 years after initial treatment.

\section{Case Presentation}

In April 2001, a postmenopausal 57-year-old female was diagnosed with FIGO stage 1a, grade 1 endometrial carcinoma and subsequently underwent laparoscopic-assisted vaginal hysterectomy and bilateral salpingo-oophorectomy without adjuvant therapy. The carcinoma was limited to the endometrium without myometrial or lymphovascular invasion. The patient remained under close follow-up with a non-contributory interim medical history and without any evidence of recurrent disease until April 2014. At that time, 13 years after the initial diagnosis and treatment, a routine office visit revealed microscopic hematuria on urine analysis. The results of the initial urine analysis were found to be false after a follow-up urine analysis, and the cytoscopic evaluation was negative. The patient had no family history of cancer or personal history of endometriosis. She was asymptomatic with a body mass index of $19.6 \mathrm{~kg} / \mathrm{m}^{2}$ and denied vaginal bleeding, abdominal pain, changes in bowel habits, or weight loss. A pelvic examination revealed a right posterior mass approximately $7-8 \mathrm{~cm}$. A magnetic resonance imaging scan of the abdomen revealed a $6 \times 5.2 \times 7.8 \mathrm{~cm}$ enhancing lobular heterogeneous mass in the right posterior pelvis. A computed tomography-guided biopsy of the mass was performed in June 2014 (Figure 1); however, the results were inconclusive due to inadequate tissue sampling.

Surgery was performed in July 2014 and included exploratory laparotomy, omentectomy, appendectomy, and pelvic mass resection. Intraoperative findings showed a $5 \mathrm{~cm}$ mass attached to the sigmoid colon. No residual disease remained at the conclusion of surgery with an estimated blood loss of 


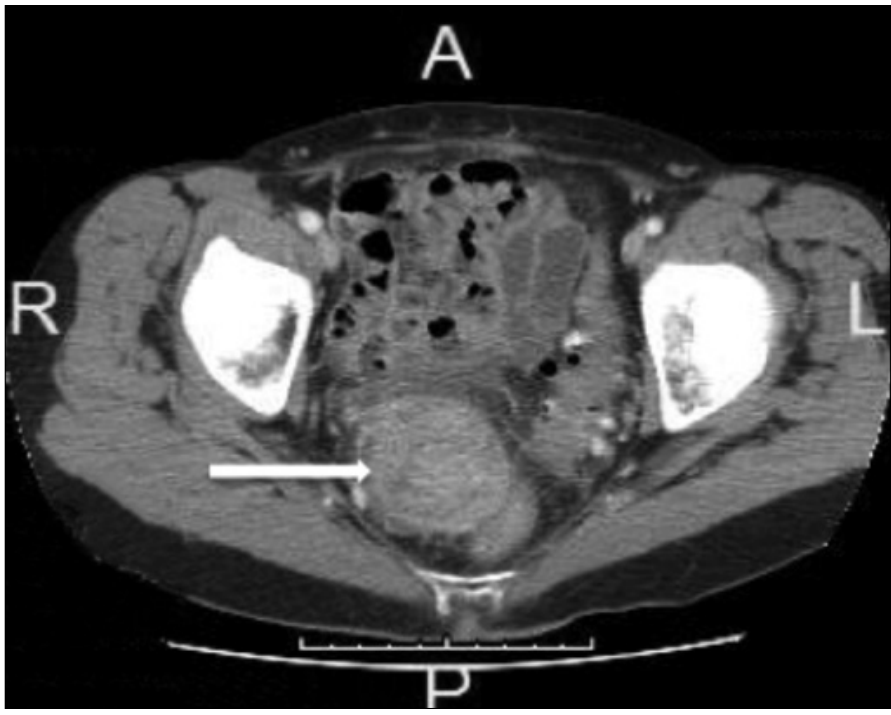

Figure 1. CT abd/pelvis with contrast. There is a heterogeneous right pelvis mass measuring $5.2 \times 4.6 \mathrm{~cm}$ to the right of the rectum (mass indicated by white arrow)

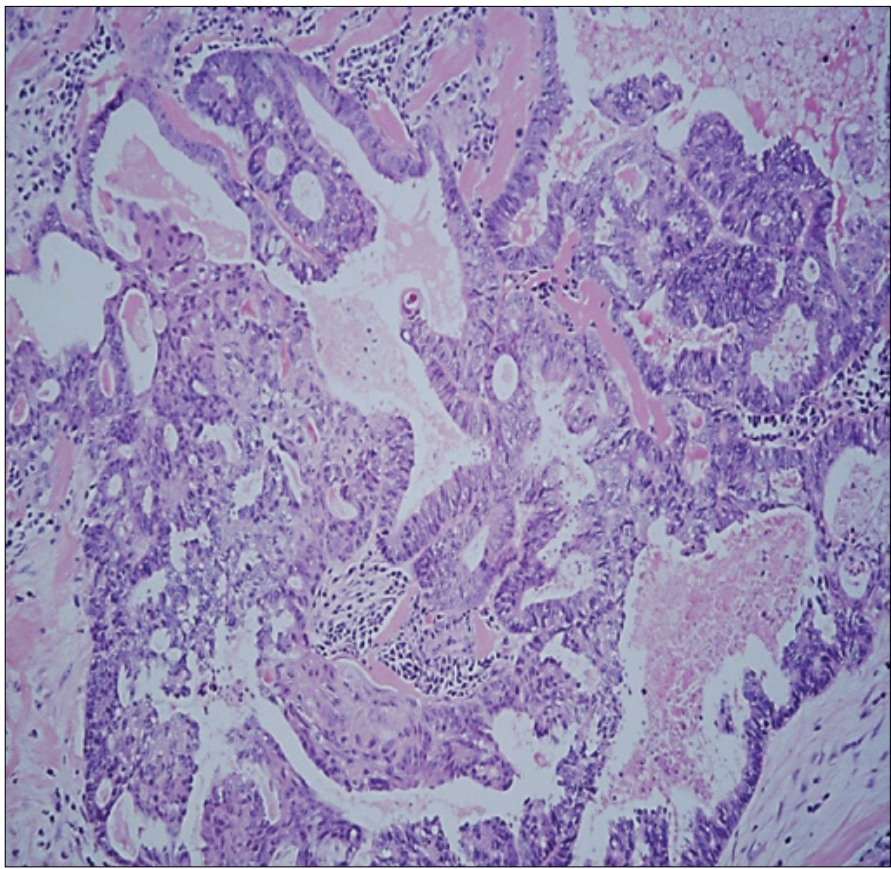

Figure 2. Histological examination. $100 \times$ microscopic view of an area of tumor showing cribriformed glands with associated squamous metaplasia, characteristic of endometrioid adenocarcinoma

$150 \mathrm{~mL}$. Surgery was well tolerated, and the patient was discharged on postoperative day 4 .

The final pathology revealed moderately differentiated adenocarcinoma in the pelvic mass compatible with recurrent endometrioid endometrial adenocarcinoma. Omental and peritoneal biopsies were negative for tumor. Special stains were positive for estrogen and progesterone receptors and negative for p53 (Figure 2). Informed consent was obtained from the patient for reporting of her case.

\section{Discussion}

The Gynecologic Oncology Group (GOG) 99 trial showed that most initial relapses of endometrial carcinoma occur within 18 months, with the Postoperative Radiation Therapy in Endometrial Carcinoma (PORTEC) study reporting a median time to recurrence of 21 months (3). Those with low-risk carcinoma (G1 or G2 histology, myometrial invasion $<50 \%$, no cervical disease, and no lymphovascular invasion) have a very low probability of recurrence, $1-3 \%$, following surgical treatment alone. Bell et al. (4) found that the omission of lymphadenectomy is a reasonable option in patients with low-risk disease diagnosed by intraoperative factors. In this study, $1.7 \%$ of the patients experienced recurrent disease with a mean time to recurrence of 43.7 months and 5-year overall survival of $95.8 \%$, consistent with the excellent outcomes of stage 1 disease reported in other studies. Carcinoma recurring after 13 years in our patient represents a significantly longer time to relapse than what has previously been reported and, to our knowledge, is the longest disease-free interval with pelvic recurrence found in literature.

Although rare, recurrences of endometrial carcinoma occurring more than 10 years after initial treatment have been reported (Table 1). Only four cases of relapse more than 10 years after surgical management with or without adjuvant therapy have been described. The first reported case of stage la disease treated with an intracavitary radium implant followed by radical hysterectomy recurred 26.5 years later in an isolated lower vaginal recurrence, which was histologically identical to the original tumor (5). Another study reported the case of a 61-year-old woman who had a vaginal cuff recurrence 17 years after total abdominal hysterectomy and bilateral salpingo-oophorectomy with adjuvant pelvic external beam radiation therapy and who was successfully treated by vaginal brachytherapy (6). After salvage high-dose-rate brachytherapy to the cuff, the patient remained disease free until her death 7 years later from unrelated causes. Other reported studies discussed the possibility of the implantation of cancer cells to another site caused by a diagnostic or surgical procedure as the pathogenesis behind late recurrence. There is a reported case of the recurrence of endometrioid carcinoma at an abdominal scar 14 years after hysterectomy, most likely due to direct tumor cell seeding at the time of operation (7). This recurrence was resected without adjuvant therapy. Another patient with unusual recurrence in the upper urinary tract 11 years after hysterectomy that was likely due to implantation during partial ureterectomy during pelvic lymph node dissection was successfully treated with surgical resection and external beam radiation therapy (8).

In the setting of recurrent disease, certain clinical and pathological factors are associated with a good prognosis, including a longer disease free-interval, low-grade and endometrioid histology, and isolated recurrence at the vaginal cuff (9). Recurrent endometrial carcinoma presents with different patterns, including disease localized to the vagina, limited to the pelvis, or metastatic disease. The most common site for endometrioid carcinoma recurrence is local, involving the vaginal vault or cuff. The PORTEC trial showed a decreased incidence of an 
Table 1. Reported recurrences with a disease-free interval longer than 10 years

\begin{tabular}{|l|l|l|l|l|l|l|}
\hline $\begin{array}{l}\text { Author } \\
\text { (Cases) }\end{array}$ & $\begin{array}{l}\text { FIGO stage, } \\
\text { grade }\end{array}$ & $\begin{array}{l}\text { Initial } \\
\text { treatment }\end{array}$ & $\begin{array}{l}\text { Disease-free } \\
\text { Interval }\end{array}$ & $\begin{array}{l}\text { Site of } \\
\text { recurrence }\end{array}$ & $\begin{array}{l}\text { Management } \\
\text { of recurrence }\end{array}$ & Outcome \\
\hline $\begin{array}{l}\text { Lederman } \\
\text { et al. (5) }\end{array}$ & $\begin{array}{l}\text { FIGO stage 1a, } \\
\text { grade 2 } \\
\text { endometrioid }\end{array}$ & $\begin{array}{l}\text { Intracavitary radium } \\
\text { implant followed by } \\
\text { radical hysterectomy }\end{array}$ & 26.5 years & Lower vagina & $\begin{array}{l}\text { Retreated with } \\
\text { radiation } \\
\text { therapy }\end{array}$ & $\begin{array}{l}\text { No evidence of } \\
\text { disease } 1.5 \text { years } \\
\text { after diagnosis } \\
\text { of recurrence }\end{array}$ \\
\hline $\begin{array}{l}\text { Yechieli } \\
\text { et al. (6) }\end{array}$ & $\begin{array}{l}\text { FIGO stage 1c, } \\
\text { grade 2 } \\
\text { endometrioid }\end{array}$ & $\begin{array}{l}\text { Total abdominal } \\
\text { hysterectomy and } \\
\text { bilateral salpingo- } \\
\text { oophorectomy } \\
\text { followed by adjuvant } \\
\text { external beam } \\
\text { radiation to the } \\
\text { whole pelvis }\end{array}$ & 17 years & Vaginal cuff & $\begin{array}{l}\text { Salvage high-dose } \\
\text { rate intracavitary } \\
\text { vaginal } \\
\text { brachytherapy }\end{array}$ & $\begin{array}{l}\text { No evidence of } \\
\text { the disease for } \\
\text { more than } 7 \\
\text { years after } \\
\text { salvage treatment; } \\
\text { death from } \\
\text { unrelated causes } \\
\text { at age } 88\end{array}$ \\
\hline $\begin{array}{l}\text { Lorenz } \\
\text { et al. (7) }\end{array}$ & $\begin{array}{l}\text { FIGO stage 1a, } \\
\text { grade 2 } \\
\text { endometrioid }\end{array}$ & $\begin{array}{l}\text { Total abdominal } \\
\text { hysterectomy and } \\
\text { bilateral salpingo- } \\
\text { oophorectomy } \\
\text { followed by radiation } \\
\text { therapy of the vagina }\end{array}$ & 14 years & $\begin{array}{l}\text { Abdominal } \\
\text { wall scar }\end{array}$ & $\begin{array}{l}\text { Surgical excision of } \\
\text { mass and portion } \\
\text { of anterior } \\
\text { abdominal wall }\end{array}$ & $\begin{array}{l}\text { No evidence of } \\
\text { disease }\end{array}$ \\
\hline $\begin{array}{l}\text { Tsurumaki } \\
\text { et al. (8) }\end{array}$ & $\begin{array}{l}\text { FIGO stage 2, } \\
\text { grade 2 } \\
\text { endometrioid }\end{array}$ & $\begin{array}{l}\text { Radical } \\
\text { hysterectomy }\end{array}$ & 11 years & $\begin{array}{l}\text { Upper urinary } \\
\text { tract (left pelvic } \\
\text { ureter to renal } \\
\text { pelvis) }\end{array}$ & $\begin{array}{l}\text { Nephroureterectomy } \\
\text { with excision of } \\
\text { bladder cuff followed } \\
\text { by radiation (50 gray) }\end{array}$ & $\begin{array}{l}\text { No evidence of } \\
\text { disease }\end{array}$ \\
\hline FIGO: International Federation of Gynecology and Obstetrics & & & \\
\hline
\end{tabular}

isolated vaginal recurrence but worse overall survival if prior adjuvant radiation therapy was administered. The lack of survival benefit led the authors to conclude that the use of radiation therapy should be limited to those patients at a sufficiently high risk of recurrence (3).

The approach to women with recurrent locoregional disease limited to the pelvis is similar to the management for those with metastatic disease. Particularly for the patient with no prior radiation treatment, there is a role for radiation therapy in the treatment of a local or regional recurrence. Hormonal therapy with progestational agents versus tamoxifen is an alternative option for some women with recurrence. Response to endocrine therapy can be expected to be more favorable in patients with a well-differentiated histology (grade 1 or 2 endometrioid), positive estrogen or progesterone receptor expression, and long disease-free interval. The patient presented in the current case would be expected to have a favorable response to hormonal therapy, given the presence of all three factors in her disease. Carboplatin and paclitaxel regimen is usually recommended as first-line chemotherapy for recurrent endometrial carcinoma (9). Recent research has also shown metformin to be a potent inhibitor of cell proliferation in endometrial carcinoma cell lines. Considering the strong risk factors, obesity and diabetes, that drive the development of type I endometrial carcinomas, Cantrell et al. (10) theorized that metformin potently inhibits growth in a dose-dependent manner via multiple signaling pathways. Future investigations are underway, utilizing metformin as a strategy for endometrial carcinoma prevention and treatment. Finally, the recombinant monoclonal antibody against endothelial growth factor, bevacizumab, appears to be active against recurrent or persistent endometrial carcinoma (objective response rate of $15 \%$ ) in recent studies. It is currently being evaluated with other agents in a recently closed phase II GOG study (9).

The treatment of patients with recurrent endometrial carcinoma is guided by a number of factors such as disease-free interval, the history of prior therapy, the site of recurrence, and grade and histology. The paucity of prospective randomized data with no treatment regimen demonstrating superiority over another suggests that clinical trials are beneficial for this patient population. The patient presented in this case is being considered for enrollment in a GOG clinical trial for recurrent endometrial carcinoma and will receive 6 cycles of carboplatin and paclitaxel with or without metformin hydrochloride if enrolled. It can be posited that the etiology of the current disease, which we have considered to be a "recurrence," may have been due to the malignant transformation of endometriosis and hence represent a metachronous primary disease. With no history of endometriosis and no evidence of ectopic uterine tissue seen on initial laparoscopy or original pathology, the de novo development of endometrioid carcinoma from ectopic endometriosis is unlikely (11). Another possibility to consider is the senescence of tumor cells remaining after initial surgery. The theory of dormant cancer cells postulates that malignant cells can persist for many years in dormancy, neither dividing nor undergoing apoptosis (12).

Sartori et al. (13) demonstrated a significant impact of diseasefree interval on the overall survival of patients. Patients with later relapse ( $>24$ months versus $<24$ months) were shown to have improved 5- and 10-year survival rates along with overall survival. The prognosis for the vast majority of recurrent 
endometrial carcinoma patients is generally poor. However, a literature review shows successful salvage therapy for the very few cases reported for recurrences occurring more than 10 years later. Moreover, our patient demonstrates the first case of low risk endometrioid carcinoma with recurrence in the pelvis occurring more than 10 years later that shared a favorable outcome as the studies described previously. This report and review of prior cases, as listed in Table 1, emphasize the possibility of a very late recurrence of endometrial carcinoma despite favorable initial prognostic features. Though these recurrences are unexpected and startling, the good prognosis as previously described can be reassuring to patients and healthcare providers.

\section{Ethics Committee Approval: N/A.}

Informed Consent: Written informed consent was obtained from patient who participated in this case.

Peer-review: Externally peer-reviewed.

Author Contributions: Concept - A.K., L.C.; Design - A.K.; Supervision - L.C., L.N., T.K.; Resource - L.C., T.K.; Materials - L.C., T.K.; Data Collection and/or Processing - L.C., T.K.; Analysis and/or Interpretation - L.N., L.C., T.K.; Literature Search - A.K., L.N., L.C., T.K.; Writing - A.K., L.N., L.C., T.K.; Critical Reviews - A.K., L.N., L.C., T.K.

Conflict of Interest: No conflict of interest was declared by the authors.

Financial Disclosure: The authors declared that this study has received no financial support.

\section{References}

1. World cancer research fund international. Cancer facts and figures: Endometrial cancer rates. Available from: http://www.wcrf. org/cancer_statistics/cancer_facts/endometrial_cancer_rates.php.

2. Siegel R, Ma J, Zou Z, Jemal A. Cancer statistics, 2014. CA Cancer J Clin 2014; 64: 9-29. [CrossRef]

3. Keys HM, Roberts JA, Brunetto VL, Zaino RJ, Spirtos NM, Bloss JD, et al. Gynecologic Oncology Group: A phase III trial of surgery with or without adjunctive external pelvic radiation therapy in intermediate risk endometrial adenocarcinoma: a Gynecologic Oncology Group study. Gynecol Oncol 2004; 92: 744-51. [CrossRef]

4. Bell JG, Patterson DM, Klima J, Harvison M, Rath K, Reid G. Outcomes of patients with low-risk endometrial cancer surgically staged without lymphadenectomy based on intra-operative evaluation. Gynecol Oncol 2014; 134: 505-9. [CrossRef]

5. Lederman GS, Niloff JM, Redline R, Rosen EM. Late recurrence in endometrial carcinoma. Cancer 1987; 59: 825-8. [CrossRef]

6. Yechieli R, Robbins JR, Schultz D, Munkarah A, Elshaikh MA Vaginal Recurrence More than 17 Years after Hysterectomy and Adjuvant Treatment for Uterine Carcinoma with Successful Salvage Brachytherapy: A Case Report. Case Rep Oncol 2011; 4: 242-5. [CrossRef]

7. Lorenz U, Gassel AM, Thiede A, Gassel HJ. Endometrial carcinoma recurrence in an abdominal scar 14 years after total hysterectomy. Gynecol Oncol 2004; 95: 393-5. [CrossRef]

8. Tsurumaki Y, Kume H, Homma Y. Late recurrence of uterine endometrioid carcinoma in the upper urinary tract. Arch Gynecol Obstet 2009; 280: 631-2. [CrossRef]

9. Bradford LS, Rauh-Hain JA, Schorge J, Birrer MJ, Dizon DS. Advances in the management of recurrent endometrial cancer. Am J Clin Oncol 2013; 38: 206-12. [CrossRef]

10. Cantrell LA, Zhou C, Mendivil A, Malloy KM, Gehrig PA, Bae-Jump VL. Metformin is a potent inhibitor of endometrial cancer cell proliferation--implications for a novel treatment strategy. Gynecol Oncol 2010; 116: 92-8. [CrossRef]

11. Hoang CD, Boettcher AK, Jessurun J, Pambuccian SE, Bullard KM. An unusual rectosigmoid mass: endometrioid adenocarcinoma arising in colonic endometriosis: case report and literature review. Am Surg 2005; 71: 694-7.

12. Morris VL, Schmidt EE, MacDonald IC, Groom AC, Chambers AF. Sequential steps in hematogenous metastasis of cancer cells studied by in vivo videomicroscopy. Invasion Metastasis 1997; 17: 281-96.

13. Sartori E, Laface B, Gadducci A, Maggino T, Zola P, Landoni F, et al. Factors influencing survival in endometrial cancer relapsing patients: a Cooperation Task Force (CTF) study. Int J Gynecol Cancer 2003; 13: 458-65. [CrossRef] 